\title{
An Active Fraction from DalbergiaTrichocarpa Baker Disrupts the Formation and Maintenance of Biofilms in Pseudomonas Aeruginosa PAO1
}

\author{
Tsiry Rasamiravaka ${ }^{1}$, Labtani Quentin ${ }^{1}$, Adeline Mol $^{1}$, Véronique Megalizzi ${ }^{2}$, Christian Rabemanantsoa ${ }^{3}$, Pierre
} Duez $^{4}$ and Mondher El Jaziri ${ }^{1}$

Laboratoire de Biotechnologie Végétale, Université Libre de Bruxelles (ULB), 12

Rue des Professeurs Jenner et Brachet, B-6041 Gosselies, Belgium ${ }^{1}$

Laboratoire de Toxicologie, Faculté de Pharmacie, Université Libre de Bruxelles, CP 205/1, Boulevard du triomphe, B-

$$
1050 \text { Brussels, Belgium }{ }^{2}
$$

Laboratoire de Biodiversité et de Biotechnologie, Institut Malgache de Recherches Appliquées (IMRA), B.P. 3833

$$
\text { AvarabohitraItaosy, Antananarivo 102, Madagascar }{ }^{3}
$$

Service de Chimie Thérapeutique et de Pharmacognosie, Université de Mons (UMONS), Bât. 6, 25 Avenue Maistriau,

$$
\text { B-7000 Mons, Belgium }{ }^{4}
$$

\begin{abstract}
The bark of Dalbergiatrichocapra Baker is traditionally used in Madagascar as an anti-infective remedy. Beyond the recently known anti-quorum sensing (QS) properties of the D. trichocarpabark n-hexane extract, QSindependent anti-infective activities have been also detected. Indeed, chromatographic fractionation allowed the elution of fraction F1 that affects neither bacterial growth nor the expression of QS-related genes (lasB and rhlA) but significantly reduces the formation of biofilm ( $55.8 \pm 2.3 \%$, as compared to control conditions). Moreover,F1 is able to disrupt the structure of one-day old preformed biofilms, which consequently increases the effectiveness of an antibiotic, levofloxacin, on biofilm-encapsulated bacteria (dead bacteria in presence of levofloxacin-F1 were two-fold higher compared to levofloxacin alone). This F1-triggered disruption of biofilm formation is presumably due to an induced reduction in flagellar-dependent motilities (swimming and swarming) as well as in exopolysaccharides production. The inhibitory effect on biofilm appears reversible as the biofilm formation resumes when F1 is discarded from the culture medium. This interesting non-bactericidal mechanism of action may justify the traditional uses of D. trichocarpa in Malagasy medicine. Further work aims at identifying the compound(s) responsible for this biofilm disruption.
\end{abstract}

Keywords: Antivirulence, Biofilm, Dalbergiatrichocarpa, Extract, Pseudomonas aeruginosa.

\section{INTRODUCTION}

Medicinal plants have been used for millennia to treat and In Madagascar, endemic Dalbergia species are appease various ailments and diseases related to traditionally used as herbal medicine to treat various pathogenic bacteria [1]. Although many of these medicinal infectious diseases [5]. The bark of Dalbergiatrichocarpais plants have demonstrated their curative effectiveness notably used in some local communities (Western region through a bactericide or bacteriostatic mode of action, of Madagascar) to treat laryngitis and diarrhea [6]. recent findings indicate that plant active constituents can Recently, Rasamiravakaet al.

also contribute to limit the development and spreading of bacteria within infected hosts as well as the expression of bacterial virulence factors [2]. Indeed, infection is mainly related to the ability of bacteria to colonize and disseminate through their hosts by using different types of motility, by building structured biofilm and by releasing a myriad of virulence factors which lead to host cell and tissue damages [3]. Therefore, in their struggle against bacterial infection, plants have developed two global strategies; one that aims to kill bacteria by disrupting crucial mechanism for bacterial survival, and a second that aims to control the expression of bacterial virulence factors [4]. Such a strategy, also valuable to protect animal and human species from bacterial infections, certainly warrants detailed investigation.

[7] reported on the reduction of virulence factor expression and biofilm formation in PAO1 from crude D. trichocarpaextract. Chromatographic fractionation of the crude extract leads to several fractions that differentially affect virulence factor expression and biofilm formation in PAO1, suggesting the occurrence of more than one active constituent in the crude bark extract. Previous investigation of fraction number 4 leads to the isolation of oleanolic aldehyde coumarate (OALC) as the QSdependent active constituent in this fraction.

In the present study, we report on the characterization of the chromatographic fraction number 1 that show different chromatographic profile and display QS-independent antivirulence potential as compared to fraction 4 . 


\section{MATERIALS AND METHODS}

A. Bacterial Strains, Plasmids and Culture Conditions $\mathrm{P}$. aeruginosaPAO1 wild-type are grown $\left(37^{\circ} \mathrm{C}\right.$, agitation at $175 \mathrm{rpm})$ in LB-MOPS broth $(50 \mathrm{mM}, \mathrm{pH} 7.2$, SigmaAldrich). For the detection of anti-QS activity, two PAO1derived strains harboring QS-related promoter-lacZfusions (lasB-lacZ and rhlA-lacZ) and one PAO1-derived strain harboring QS-independent promoter-lacZfusions (aceAlacZ) were used. Description of the used strains and of the experimental procedure for the determination of QS activity were as previously reported by Vandeputteet al. [8] and by Rasamiravakaet al. [9].

\section{B. Plant Materials}

Stem bark samples of Dalbergiatrichocarpa Baker. were collected from trees growing close to the city of Morondava (Kirindy forest with the following GPS coordinates: $20^{\circ} 04.120^{\prime} \mathrm{S} 44^{\circ} 39.250^{\prime}$ E, elevation $88 \mathrm{~m}$ ). Plant materials were identified and deposited at PBZT herbarium (Botanical and Zoological Park of Tsimbazaza, Antananarivo, Madagascar; Reference number 183/13/MEF/SG).

C. Extraction and Fractionation of D. TrichocarpaStem Bark

Dried powdered samples of D. trichocarpa stem bark (5 $\mathrm{kg}$ ) were extracted with $\mathrm{n}$-hexane by percolation (2 liters for 1 hour) and the collected hexane extract was filtered and evaporated under reduced pressure to obtain an oily residue $(10 \mathrm{~g})$. For fractionation, the collected residue was mixed with silica gel, loaded onto a silica gel $60 \mathrm{~F}_{254}$ column (63-200 $\mu \mathrm{m} / 70-230$ mesh; Merck; $35 \mathrm{~cm}$ by $4 \mathrm{~cm}$ i.d.) and chromatographed, eluting with n-hexane, a step gradient of n-hexane : ethyl acetate (100:10 to 10:100, V/V) (fractions F1 to F6) and a step gradient of ethyl acetate : methanol $(100: 10$ to $10: 100, \mathrm{~V} / \mathrm{V})$ (fractions F7 to F9). The fraction F1 (2.2 g) was eluted with the mixture hexane/ethyl acetate (90:10). For biological testing, the different extracts and fractions were dissolved in DMSO to get appropriate concentration detailed below.

\section{Antibacterial Assay}

For the determination of MIC (Minimum Inhibitory Concentration) and MBC (Minimal Bactericidal Concentration), PAO1 was grown on 24-well microplateswith $1 \mathrm{ml}$ of LB broth in the presence of DTB extract or each fraction at different concentrations (31.25 to $4000 \mu \mathrm{g} / \mathrm{ml}$ ) and incubated at $37^{\circ} \mathrm{C}$ for $24 \mathrm{~h}$. The MIC was defined as the lowest concentration that completely inhibited growth as detected by the naked eye [10]. All inhibited growth culture were then sub-cultured onto LB agar plate and incubated at $37^{\circ} \mathrm{C}$ for $24 \mathrm{~h}$ to determine the MBC which was defined as the lowest concentration that yielded negative sub-cultures [11]. Tobramycin was used as positive control.

\section{E. Biofilm Formation and Quantification}

The formation of biofilm was studied on 24-well microplates and quantified by a crystal violet staining protocol as previously described [9]. Briefly, an overnight culture of PAO1 was washed twice and diluted in fresh biofilm broth (BB) medium $\left(\mathrm{Na}_{2} \mathrm{HPO}_{4}, 1.25 \mathrm{~g} / \mathrm{l} ; \mathrm{FeSO}_{4} .7 \mathrm{H}_{2} \mathrm{O}\right.$,
$0.0005 \mathrm{~g} / \mathrm{l} ;$ glucose, $0.05 \mathrm{~g} / \mathrm{l} ; \quad(\mathrm{NH} 4)_{2} \mathrm{SO}_{4}, \quad 0.1 \mathrm{~g} / \mathrm{l}$; $\mathrm{MgSO}_{4} .7 \mathrm{H}_{2} \mathrm{O}, 0.2 \mathrm{~g} / \mathrm{l}$ and $\left.\mathrm{KH}_{2} \mathrm{PO}_{4}, 0.5 \mathrm{~g} / \mathrm{l}\right)$. In 24-well polystyrene plates, $50 \mu \mathrm{l}$ of the diluted culture $\left(\mathrm{A}_{600}\right.$ between 0.14 and 0.16 ) was added to $940 \mu \mathrm{l}$ of $\mathrm{BB}$ medium and was supplemented with $10 \mu \mathrm{l}$ of the desired condition. DMSO (1\% final concentration) and oleanolic acid $(800 \mu \mathrm{M}$ final concentration) were used as negative and positive control, respectively [12]. DTB was tested at different concentrations (from 50 to $300 \mu \mathrm{g} / \mathrm{ml}$, final concentration) and each fraction at $200 \mu \mathrm{g} / \mathrm{ml}$. PAO1 cultures were incubated statically for $24 \mathrm{~h}$ at $37^{\circ} \mathrm{C}$ and biofilm quantification was performed by measuring the formed biofilm stained by crystal violet at $\mathrm{A}_{590 \mathrm{~nm}}$ with a SpectraMax M2 device (Molecular Devices).

Additionally, the proportion of planktonic and biofilmencapsulated bacteria, in the presence of DMSO (control condition) or F1, was assessed by colony forming units (CFU) measurement. After $24 \mathrm{~h}$ static growth culture, planktonic bacteria were directly quantified by $\mathrm{CFU}$ measurement whereas biofilm-encapsulated bacteria were previously taked-off from culture plate by sonication with $500 \mu \mathrm{l}$ of SDS solution ( $0.2 \%$ final concentration) and then quantified by $\mathrm{CFU}$.

F. Biofilm Fluorescence Microscopy and Antibiotic Susceptibility

The formation of biofilms in PAO1 culture supplemented with $10 \mu \mathrm{l}$ of DMSO $(1 \%, \mathrm{v} / \mathrm{v})$ or F1 $(200 \mu \mathrm{g} / \mathrm{ml}$ final concentration) and bacterial viabilities were also evaluated by fluorescence microscopy using the LIVE/DEAD BacLight bacterial viability staining kit (Invitrogen). The growth medium was removed and replaced by $500 \mu \mathrm{l}$ of a solution of SYTO 9 and propidium iodide diluted 400 -fold in BB medium. Biofilms were incubated for $15 \mathrm{~min}$ and PAO1 cells were examined using a Leica DM IRE2 inverted fluorescence microscope coupled to a CCD camera (Leica DC350 FX) and equipped with FITC and Texas red filters. Viability quantification was conduct by measuring the ratio between live and dead bacteria (fluorescence emission at 530 and $630 \mathrm{~nm}$, respectively) with SpectraMax M2 device (Molecular Devices). This ratio was compared to a standard curve made from solution containing known concentrations of dead and live bacteria as described in the manufacture protocol of LIVE/DEAD BacLight bacterial viability staining kit (Invitrogen).

To evaluate the biofilm formation kinetics, the growth medium was removed after $8,16,24$ and $48 \mathrm{~h}$ of bacterial growth and the cells stained using the LIVE/DEAD BacLight kit. To evaluate the impact of F1 on preformed biofilm, PAO1 cells were grown statically for $24 \mathrm{~h}$ to form biofilm; the bacterial culture was then supplemented with $10 \mu \mathrm{l}$ of DMSO $(1 \%, \mathrm{v} / \mathrm{v})$ or F1 $(200 \mu \mathrm{g} / \mathrm{ml}$ final concentration) for a further $24 \mathrm{~h}$ incubation and the biofilm phenotypes were visualized using the LIVE/DEAD BacLight kit. To evaluate the sustained impact of F1 on biofilm development, PAO1 biofilms formed during $24 \mathrm{~h}$ in presence of $\mathrm{F} 1$ at $200 \mu \mathrm{g} / \mathrm{ml}$,were washed twice; the biofilm were added with fresh BB medium supplemented with F1 $(200 \mu \mathrm{g} / \mathrm{ml})$ or DMSO $(1 \%)$, incubated for an additional $72 \mathrm{~h}$ and visualized 
using the LIVE/DEAD BacLight kit.

The antibiotic susceptibility of biofilm-encapsulated PAO1 cells was assessed using levofloxacin, an anionic antibiotic of the family of fluoroquinolones that showed potent activity in the treatment of biofilm-complicated diseases, notably respiratory infections [13]. PAO1 cells were grown statically for $24 \mathrm{~h}$ to form biofilms, incubated with levofloxacin $(30 \mu \mathrm{g} / \mathrm{ml})$, DMSO $(1 \%)$ or F1 (200 $\mu \mathrm{g} / \mathrm{ml}$ ) for a further $24 \mathrm{~h}$ and assessed using the LIVE/DEAD BacLight kit.

\section{G. Rhamnolipids Extraction and Quantification}

The extraction and quantification of rhamnolipids were performed as previously described [14]. In brief, PAO1 cultures were supplemented with DMSO (1\%; negative control), naringenin (4 mM; positive control) or F1 (200 $\mu \mathrm{g} / \mathrm{ml})$ and incubated with agitation $(175 \mathrm{rpm})$ for $18 \mathrm{~h}$ in LB-MOPS medium at $37^{\circ} \mathrm{C}$. Bacterial cultures were centrifuged and $1 \mathrm{ml}$ of supernatant was mixed with $3 \times 1$ $\mathrm{ml}$ of ethyl acetate. The upper phases containing ethyl acetate-rhamnolipids were collected, transferred to a new reaction tube and evaporated to dryness; extracted rhamnolipids were quantified by a methylene-blue-based method [15] with some modifications. Briefly, the rhamnolipids extract was dissolved with $4 \mathrm{ml}$ chloroform and mixed with $400 \mu \mathrm{l}$ of a $40 \mu \mathrm{g} / \mathrm{mL}$ methylene blue aqueous solution. After $15 \mathrm{~min}$ of complexation, $1 \mathrm{ml}$ of the chloroform phase was mixed with $500 \mu \mathrm{l}$ of $\mathrm{HCl} 0.2 \mathrm{~N}$. Finally, $200 \mu \mathrm{l}$ of the upper acidic phase were transferred in 96-well polystyrene plates and the absorbances were measured at $638 \mathrm{~nm}$ with a SpectraMax M2 (Molecular Devices). A calibration curve was generated by applying the same quantification procedure with standard solutions of rhamnolipids (Sigma-Aldrich).

\section{H. Exopolysaccharides Quantification}

Congo Red was used to estimate the proportion of exopolysaccharides produced by PAO1 as this colorant has a strong interaction with polysaccharides containing contiguous units of $\beta$-( $1 \rightarrow 4)$-D-glucopyranosyl [16]. Briefly, PAO1 was grown with agitation for $24 \mathrm{~h}$ in LB medium supplemented with Congo Red $(40 \mu \mathrm{g} / \mathrm{ml}$ final concentration) in the presence of F1 $(200 \mu \mathrm{g} / \mathrm{ml})$, DMSO (1 \%; negative control), naringenin (4 $\mathrm{mM}$; positive control). Congo Red binds the bacterial polysaccharides produced to become insoluble and so, after centrifugation, the colorant remaining in the supernatant was quantified by absorbance measurements at $\mathrm{A}_{490}$.

\section{Motility Assays}

Swimming, swarming and twitching motilities were examined by using LB agar $(0.3 \%, 0.6 \%$ and $1 \%$, respectively) as described by Rasamiravakaet al. [9] and $\mathrm{Ha}$ et al. [17]. After sterilization and cooling $\left(45-50^{\circ} \mathrm{C}\right)$ of LB agar, the tested agents were added [F1 $(200 \mu \mathrm{g} / \mathrm{ml})$, DMSO ( $1 \%$; negative control) or azithromycin $(2 \mu \mathrm{g} / \mathrm{ml}$; positive control) [18]], the medium was poured into compartmented Petri dishes and cooled to room temperature. Five $\mu$ l of bacterial culture $\left(A_{600}=1\right)$ were inoculated at the center of each compartment of the Petri dishes and incubated at $37^{\circ} \mathrm{C}$ for 24 (for swimming and swarming) or $48 \mathrm{~h}$ (for twitching motility). Bacteria spreading from the inoculation spot were measured with sliding caliper after adequate incubation time.

\section{J. Assessment of Bacterial Growth}

The relative growth of $\mathrm{P}$. aeruginosa PAO1 after $18 \mathrm{~h}$ in the different experimental conditions was evaluated by measuring the cell density at $\mathrm{A}_{600}$ with a SpectraMax M2 device (Molecular Devices). The growth kinetics of $P$. aeruginosa PAO1 was evaluated by measuring the $A_{600}$ of PAO1 cells grown over a $24 \mathrm{~h}$ period with bacterial cell counts (CFU) for two points ( 8 and $18 \mathrm{~h}$ ).

K. Gene Expression and $\beta$-Galactosidase Measurements $\beta$-Galactosidase measurements were performed as previously described [8] to monitor gene expression. Briefly, after growth in liquid LB-MOPS with carbenicillin $(300 \mu \mathrm{g} / \mathrm{ml})$ at $37{ }^{\circ} \mathrm{C}$ with agitation $(175 \mathrm{rpm})$ for $18 \mathrm{~h}, \mathrm{PAO} 1$ reporter strains were washed twice in fresh LB medium and re-suspended in liquid LB-MOPScarbenicillin. PAO1 reporter strain inocula $\left(50 \mu \mathrm{l} ; \mathrm{A}_{600}\right.$ between 0.020 and 0.025$)$ were incubated $\left(37{ }^{\circ} \mathrm{C}\right.$ with agitation at $175 \mathrm{rpm}$ ) for $18 \mathrm{~h}$ in $1 \mathrm{ml}$ LB-MOPScarbenicillin supplemented with $10 \mu \mathrm{l}$ of DTB, $10 \mu \mathrm{l}$ of fractions dissolved in DMSO $(200 \mu \mathrm{g} / \mathrm{ml}$ final concentration), $10 \mu \mathrm{l}$ of DMSO (1\%; negative condition) or $10 \mu \mathrm{l}$ of naringenin (4mMfinal concentration), a known P. aeruginosa QS inhibitor (positive control) [19]. After incubation, the bacterial density was assessed by spectrophotometry $\left(\mathrm{A}_{600}\right)$ and the gene expression by a $\beta$ galactosidase assay using o-nitrophenyl- $\beta$-Dgalactopyranoside as described by Zhang and Bremer [20].

\section{Statistics}

All experiments were performed in triplicate and repeated in 3 independent assays. The data were statistically analyzed by conducting Student's t tests (i.e. each test was compared with the DMSO-treated cells) and a P-value < 0.01 was considered as being significant.

\section{RESULTS}

A. Anti-Infective Activities of the D. Trichocarpa Bark Extract

On P. aeruginosa PAO1, the MIC and MBC of the D. trichocarpa bark (DTB) n-hexane extract were higher than $4000 \mu \mathrm{g} / \mathrm{ml}$, indicating an extremely weak potential as a direct antibiotic [11]; by comparison, the MIC and MBC for tobramycin [antibiotic generally used to treat $P$. aeruginosa infection and particularly pulmonary infection in patients with cystic fibrosis [21] were $1 \mu \mathrm{g} / \mathrm{ml}$ and 2 $\mu \mathrm{g} / \mathrm{ml}$, respectively (data not show).

As shown in Fig. 1, DTB presents an anti-biofilm activity, starting at $150 \mu \mathrm{g} / \mathrm{ml}$, without affecting the bacterial growth up to $300 \mu \mathrm{g} / \mathrm{ml}$. Additionally, as shown in Fig. S1, the expressions of QS-related virulence factors genes[lasBand rhlAencoding for elastase B and 3-(3hydroxyalkanoyloxy) alkanoic acids, respectively] were reduced $(32.5 \pm 3.2 \%$ and $22.7 \pm 6.5 \%$, respectively) in the presence of DTB $(200 \mu \mathrm{g} / \mathrm{ml})$. As DTB had no effect on a QS-independent gene (isocitratelyase-encoding ace A gene), this suggests that the observed effects on QS gene expression are specific and do not result from a global 
inhibition of PAO1 metabolic activity [8] (Fig. S1c). To conclude, DTB presents a potential anti-infective activity that is not associated with bacteriostatic and/or bactericidal activity but rather with anti-QS and anti-biofilm activities.

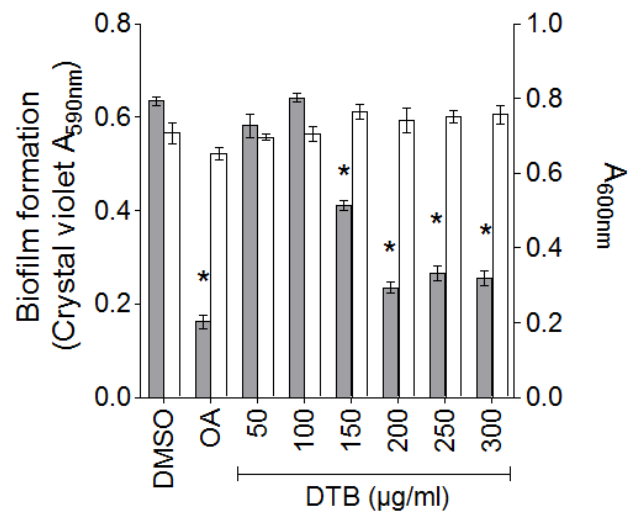

Fig. 1. Biofilm formation in the presence of Dalbergiatrichocarpa bark (DTB) extract.

Biofilm formation (grey bar) and growth turbidity (clear bar) of $\mathrm{P}$. aeruginosa PAO1 grown in minimal medium supplemented with DMSO 1\%, oleanolic acid $800 \mu \mathrm{M}$ (OA) or different concentrations of DTB (from 50 to 300 $\mu \mathrm{g} / \mathrm{ml}$ ) after incubation without agitation at $37^{\circ} \mathrm{C}$ for $24 \mathrm{~h}$. The biofilm formation was quantified by crystal violet staining and $\mathrm{A}_{590 \mathrm{~nm}}$ measurement. The cell density of the bacteria was assessed as $\mathrm{A}_{600 \mathrm{~nm}}$. All experiments were performed in triplicate with three independent assays. Error bars represent the standard error of the mean and the asterisks indicate samples that are significantly different from DMSO control (Student's t test, $\mathrm{p} \leq 0.01$ ).

B. ChromatographicIsolation of a Potent Anti-Biofilm Fraction (F1) from DTB

DTB fractionation was carried out using silica gel column chromatography; the 9 collected fractions were evaluated for their capacity to affect bacterial growth, QS-related gene expression and biofilm formation in PAO1. As for DTB, the MIC and MBC of each fraction were higher than $4000 \mu \mathrm{g} / \mathrm{ml}$ (data not shown). As shown in Fig. 2, the recorded anti-QS activity seems to be restricted to compounds eluted in fractions 3 to 6 when tested at 200 $\mu \mathrm{g} / \mathrm{ml}$ (this concentration was selected according to DTB anti-biofilm activities, Fig. 1). However, significant antibiofilm activity was recorded in several fractions (F1, F4 and F7-9) with the strongest inhibition level measured for F1 (63.2 $\pm 5.6 \%$ inhibition) (Fig. S2). In the present report, we focus on F1 which presents strongest antibiofilm and no anti-QS activities.

Anti-biofilm activity is greatly enhanced by increasing the concentration of F1 (Fig. 3), suggesting a dose-dependent activity up to $200 \mu \mathrm{g} / \mathrm{ml}$. Consequently, this last concentration has been considered for all further experiments.

Chromatographic scheme of DTB n-hexane fractionation steps. Activity was monitored using relative growth, QS inhibition and biofilm formation; significant inhibition activity was scored "+" or "++" with respect to data presented in Fig. S1, S2. F1 was eluted from the column chromatography with the mobile phase hexane:EtOAc (90:10).

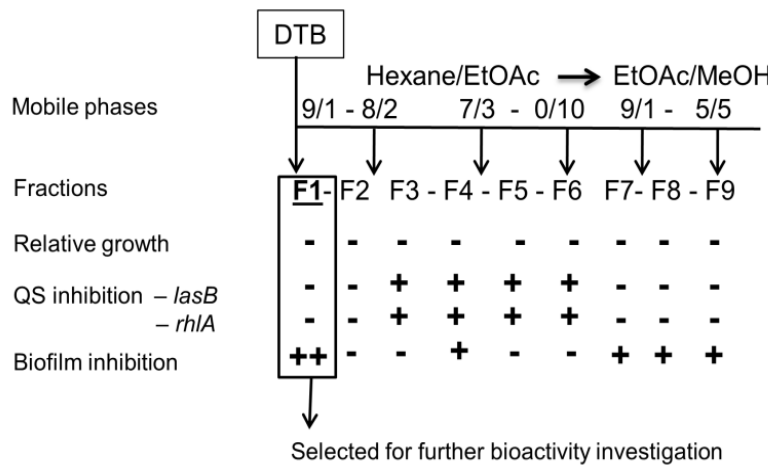

Fig. 2.Fractionation of Dalbergiatrichocarpa bark (DTB) extract and bioactivity (relative growth inhibition, QS inhibition and anti-biofilm activity) of the collected fractions.

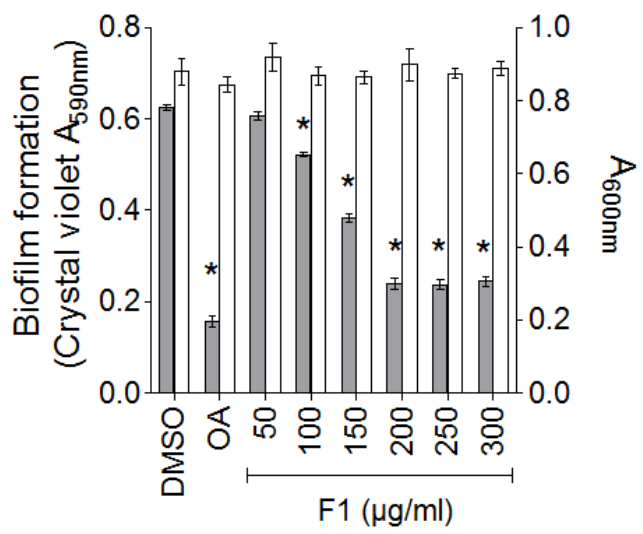

Fig. 3.Dose-dependent anti-biofilm activity of F1.

The biofilm formation (grey bar) and growth turbidity (clear bar) of $\mathrm{P}$. aeruginosa PAO1 grown in minimal medium supplemented with DMSO 1\%, oleanolic acid $800 \mu \mathrm{M}(\mathrm{OA}$ ) or different concentrations of F1 (from 50 to $250 \mu \mathrm{g} / \mathrm{ml}$ ) after incubation without agitation at $37^{\circ} \mathrm{C}$ for $24 \mathrm{~h}$. Biofilm formation was quantified by crystal violet staining and measured as $A_{590 \mathrm{~nm}}$. The cell density of the bacteria was assessed as $A_{600 n m}$. All experiments were performed in triplicate with three independent assays. Error bars represent the standard error of the mean and the asterisks indicate samples that are significantly different from DMSO control condition (Student's t test, $\mathrm{p} \leq 0.01$ ).

C. F1 Does not Affect the Growth and Viability of PAO1 To confirm that the decrease in biofilm formation is not due to an inhibition of growth at any stage of bacterial development, kinetics growth and CFU measurements were recorded in the presence of F1. As shown in Fig. 4, the cell growth and the viability of PAO1 are not affected by F1 when compared to negative control (DMSO). Indeed, no significant difference was recorded during all phases of bacterial growth (Fig. 4a) as evaluated both by turbidity and CFU measurement (Fig. 4b, c). This suggests that bacterial survival is not impaired by F1 (at 200 $\mu \mathrm{g} / \mathrm{ml})$. 


\section{International Advanced Research Journal in Science, Engineering and Technology}

\section{Vol. 3, Issue 4, April 2016}

(a)

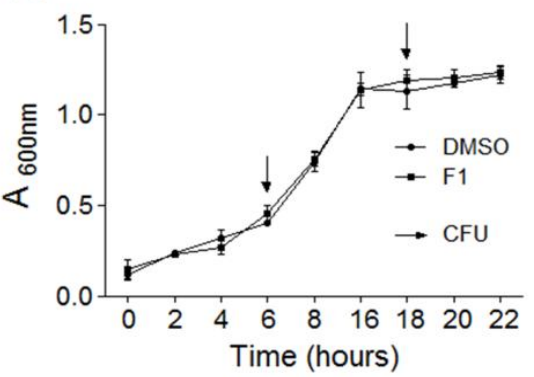

(b)

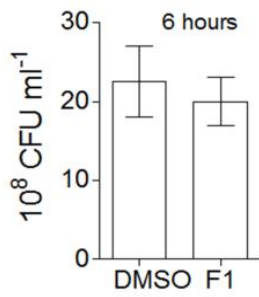

(c)

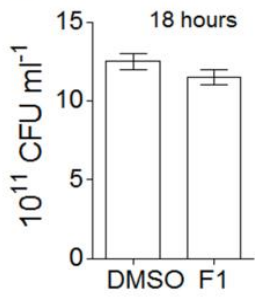

Fig. 4. Effect of $F 1$ on the growth and viability of $P$. aeruginosa PAO1

(a) Growth kinetics of PAO1 in presence of F1 $200 \mu \mathrm{g} / \mathrm{ml}$ or DMSO $1 \%$ over a period of $22 \mathrm{~h}$. The cell density of the bacteria was assessed as $\mathrm{A}_{600 \mathrm{~nm}}$ and colony forming units (CFU) were quantified after $6 \mathrm{~h} \mathrm{(b)} \mathrm{and} 18 \mathrm{~h}$ (c). The statistical significance of each test $(n=3)$ was evaluated by Student's t test (i.e. each test was compared with the control condition, DMSO), and a $\mathrm{P}$ value of $<0.01$ was considered as significant.

D. F1 Affects the Biofilm Phenotype of PAO1

In our control conditions, the development of the PAO1 biofilm begins by the adhesion of planktonic bacteria onto abiotic surfaces (Fig. 5; 8 h).

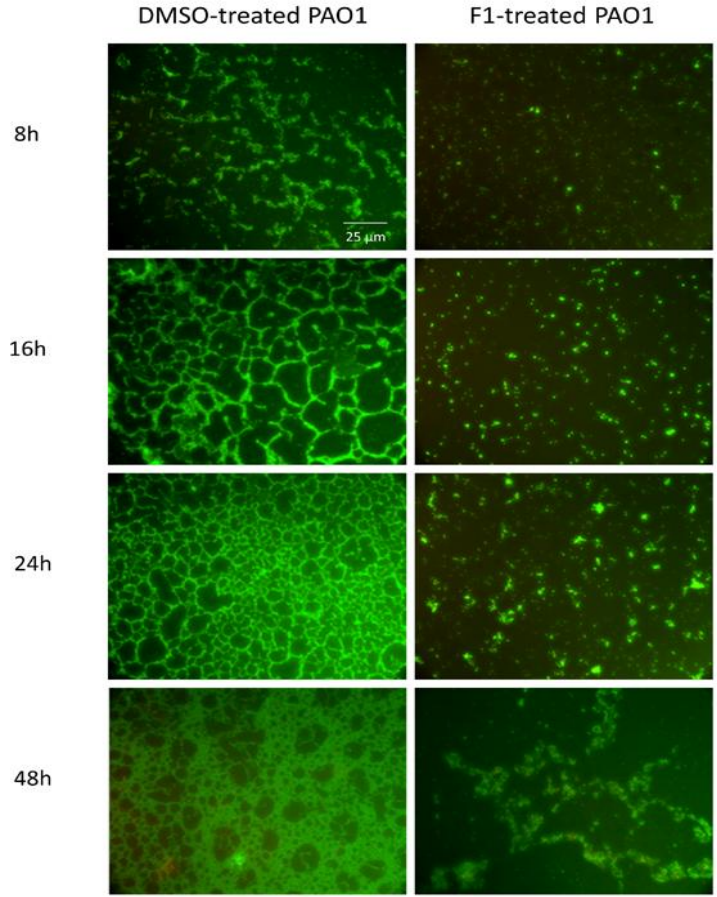

Fig. 5.Impact of $\mathrm{F} 1$ on biofilm phenotype in $\mathrm{P}$. aeruginosa PAO1
Progressively, small bacterial aggregates gather to form microcolonies within a matrix of exopolymeric substances and their confluence leads to a more structured phenotype represented by a homogeneous network of microcolonies with non-colonized space (Fig. 5; 16-24 h). Then, microcolonies continue to grow and spread over the colonizable surface (Fig. 5; 48 h).

Biofilm phenotype of $\mathrm{P}$. aeruginosa PAO1 incubated statically for $48 \mathrm{~h}$ in the presence of DMSO $1 \%$ or F1 200 $\mu \mathrm{g} / \mathrm{ml}$. Biofilm structure was revealed after staining with SYTO-9 (green fluorescence for living bacteria) and propidium iodide (red areas - dead bacteria) furnished in the LIVE/DEAD BacLight kit. Images were captured after $8,16,24$ and $48 \mathrm{~h}$ of growth using an inverted fluorescence microscope Leica DM IRE2 (400x magnification) and processed using the software Image $\mathbf{J}$.
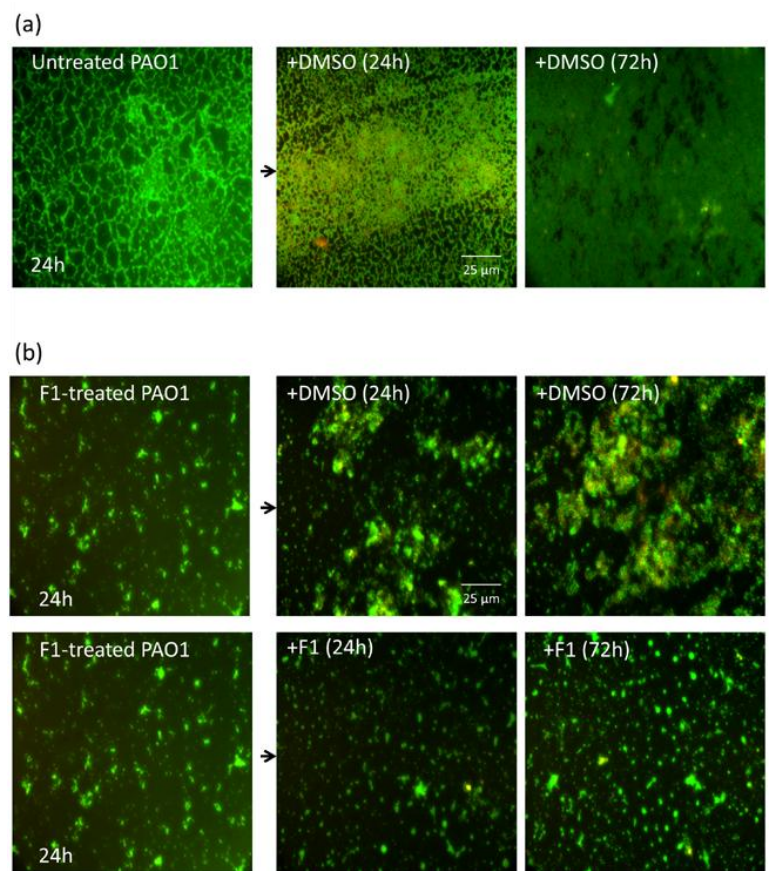

Fig. 6. Reversible inhibition of PAO1 biofilm development by $\mathrm{F} 1$

(a) One day-old biofilm untreated has been further incubated over 3 days in presence of DMSO 1\%. (b, c) One day-old biofilm treated with $\mathrm{F} 1$ has been further incubated over 3 days in the presence of DMSO $1 \%$ or F1 $200 \mu \mathrm{g} / \mathrm{ml}$. Biofilm phenotype has been recorded at 24 and $72 \mathrm{~h}$ and compared with DMSO-untreated. Biofilm phenotype was visualized as in Figure 5.

In the presence of $\mathrm{F} 1$, the adhesion and micro-colonization phases seem to be disturbed compared to control condition. Indeed, after $8 \mathrm{~h}$ of incubation in medium supplemented with F1, small bacterial aggregates that have not yet formed microcolonies are observed; between 16 and $24 \mathrm{~h}$, this phenotype remains almost unchanged; and, after $48 \mathrm{~h}$, unstructured bacterial networks were observed. These observations indicate that F1 may affect biofilm formation either by blocking/inhibiting the biofilm developmental process or by just inducing a delay in its development. To clarify these assumptions, a one day-old 


\section{International Advanced Research Journal in Science, Engineering and Technology}

biofilm developed in presence of $\mathrm{F} 1$ has been further incubated over 3 days in two different conditions, with and without F1. As shown in Fig. 6, the continuous presence of F1 impedes structuration of the biofilm over 3 days (Fig. $6 \mathrm{~b})$ whereas the removal of $\mathrm{F} 1$ allows the evolution of the biofilm toward a dense but still unstructured phenotype (Fig. 6c). This suggests that F1 causes a blockage/inhibition rather than a delay in biofilm formation. Moreover, the restart of biofilm development following the removal of F1 suggests a partially reversible effect on the biofilm developmental processes.

E. F1 Affects the Swimming and Swarming Motilities but not the Twitching Motility of PAO1

PAO1 motilities, including swimming, swarming and twitching, are complex and important processes in a biofilm lifestyle cycle [22]. Figure 7 shows that the swimming motility is drastically inhibited $(49.7 \pm 0.1 \%)$ in the presence of F1 as compared to control condition (Fig. 7a). While the swarming motility is slightly but significantly inhibited $(14.2 \pm 0.1 \%)$ (Fig. 7b), the twitching motility is not impaired (Fig. 7c). Overall, these results suggest a plausible disruption of flagellardependent motilities by F1; notably, as reported by Shroutet al. [23], a swarming motility inhibitioncorrelates with biofilms containing non-confluent cell aggregates.
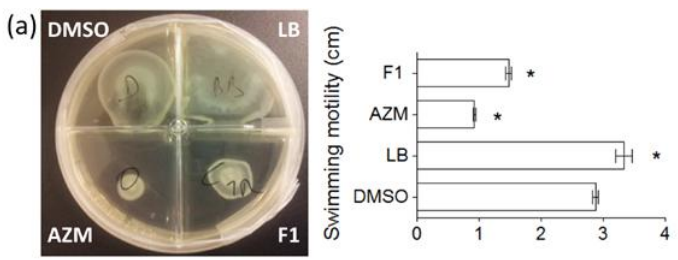

(b)
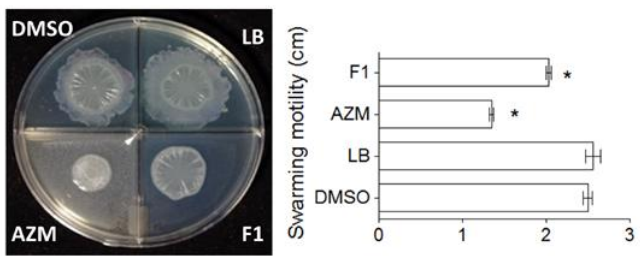

(c)
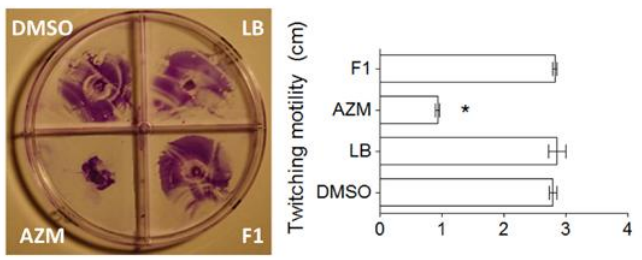

Fig. 7.Effect of F1 on PAO1 motility.

(a) Swimming, (b) swarming and (c) twitching ability of PAO1 onto LB agar $(0.3 \%, 0.6 \%$, and $1 \%$ agar, respectively) alone (LB) or supplemented with DMSO (control condition) 1\%, F1 $200 \mu \mathrm{g} / \mathrm{ml}$ or azithromycin (AZM, $2 \mu \mathrm{g} / \mathrm{ml}$ ). After incubation at $37{ }^{\circ} \mathrm{C}$ for $24 \mathrm{~h}$, bacterial spreading from the point of inoculation were measured for each condition and expressed in $\mathrm{cm}$. All experiments were performed in triplicate with three independent assays.Error bars represent the standard error of the mean and the asterisks indicate samples that are significantly different from control condition (Student's $t$ test, $\mathrm{p} \leq 0.01)$.
F. F1 Disrupts the Phenotype of Preformed Biofilms and Increases the Effectiveness of Levofloxacin Against Biofilm-Encapsulated PA01

As F1 impairs the formation of PAO1 biofilms, we further examined its impact on preformed PAO1 biofilm. As shown in Fig. 8(a-c), the addition of F1 to preformed biofilms results in a loss of compact and heterogeneous structures, leading to biofilms mainly composed by isolated bacterial clumps. Noticeably, a remarkable reduction of biofilm-encapsulated bacteria is recorded in F1-treated preformed biofilm as demonstrated by CFU's quantification (Fig. 8d). Indeed, the ratio planktonic bacteria/biofilm encapsulated bacteria varied from $0.7 / 1$ to 20/1 for control conditions and F1-treated cultures, respectively (Fig. 8d). These results suggest that F1 induces bacterial dispersion out of a preformed biofilm. Therefore, we hypothesized that biofilm-encapsulated bacteria would be more accessible to antibiotic treatments in the presence of F1. Accordingly, the effectiveness of levofloxacin $(30 \mu \mathrm{g} / \mathrm{ml})$ combined with F1 $(200 \mu \mathrm{g} / \mathrm{ml})$ was evaluated on one-day old biofilms. The addition of F1 considerably improves the effectiveness of levofloxacin against PA01 (Fig. 9). Indeed, when a preformed biofilm is treated with both $\mathrm{F} 1$ and levofloxacin $(30 \mu \mathrm{g} / \mathrm{ml})$, a drastic proportion $(89.9 \pm 1.3 \%)$ of biofilm-encapsulated bacteria are killed whereas, in the presence of levofloxacin alone, the dead bacteria rate is two-fold lower, reaching $44.4 \pm 2.4 \%$.
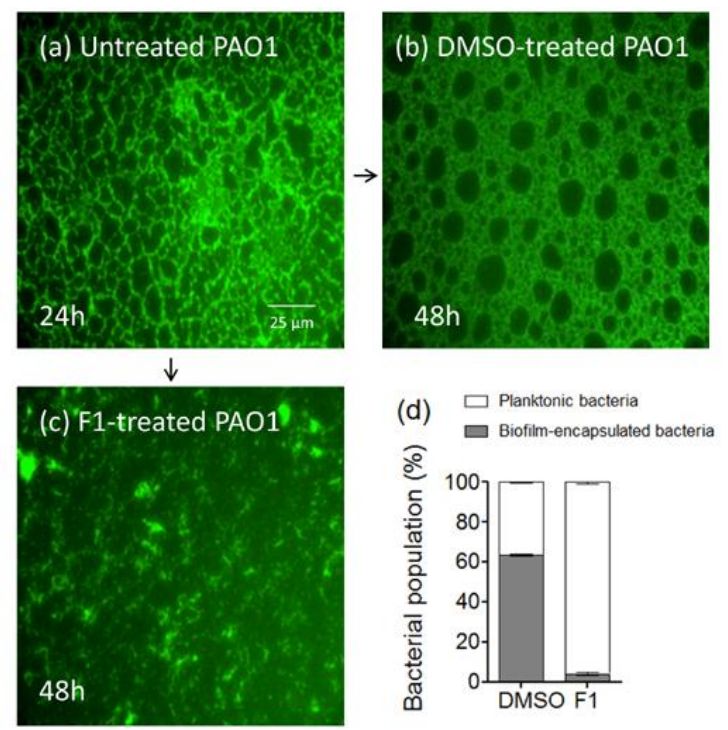

Fig. 8.Effect of F1 on a one-day old preformed biofilm in PAO1

(a) One-day old biofilm phenotype of untreated-PAO1. (b) Two-days old biofilm phenotype after $24 \mathrm{~h}$ treatment with DMSO $1 \%$ on one-day old untreated-PAO1. (c) Two-days old biofilm phenotype after $24 \mathrm{~h}$ treatment with F1 200 $\mu \mathrm{g} / \mathrm{ml}$ on one-day old untreated-PAO1. Biofilm phenotypes were visualized as in Figure 5. (d) CFU measurement of planktonic bacteria and biofilmencapsulated bacteria treated for $24 \mathrm{~h}$ with DMSO $1 \%$ or F1 $200 \mu \mathrm{g} / \mathrm{ml}$ on a one-day old culture. All experiments were performed in triplicate with three independent assays. Error bars represent the standard error of the mean 
and the asterisks indicate samples that are significantly different from control condition (Student's t test, $\mathrm{p} \leq 0.01$ ).

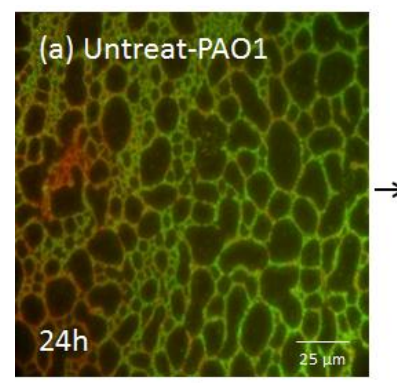

$\downarrow$

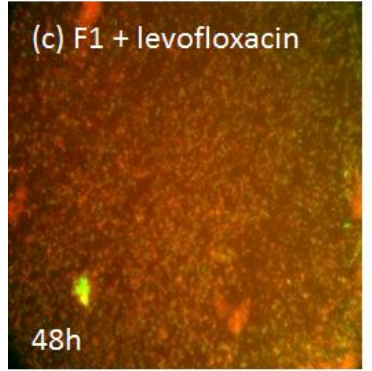

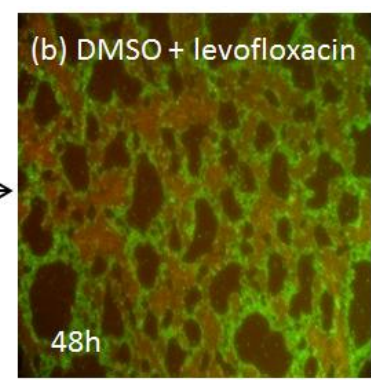

(d)

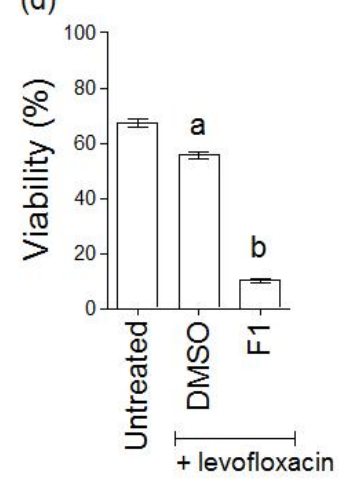

Fig. 9.Synergistic activity of F1 with levofloxacin against biofilm-encapsulated P. aeruginosa PAO1.

(a) One-day old preformed biofilm phenotype of untreated-PAO1. (b) Two-days old biofilm after $24 \mathrm{~h}$ treatment with levofloxacin $30 \mu \mathrm{g} / \mathrm{ml}+$ DMSO $1 \%$ on one-day old untreated-PAO1. (c) Two-days old biofilm after $24 \mathrm{~h}$ treatment with levofloxacin $30 \mu \mathrm{g} / \mathrm{ml}+\mathrm{F} 1200$ $\mu \mathrm{g} / \mathrm{ml}$ on one-day old untreated-PAO1. Biofilm phenotypes were visualized as in Figure 5. (d) Quantification of bacterial viability in the presence of levofloxacin $30 \mu \mathrm{g} / \mathrm{ml}+$ DMSO $1 \%$ or levofloxacin 30 $\mu \mathrm{g} / \mathrm{ml}+\mathrm{F} 1200 \mu \mathrm{g} / \mathrm{ml}$. All experiments were performed in triplicate with three independent assays. Different letters ( $\mathrm{a}$ and $\mathrm{b}$ ) above the bars indicate data that are statistically different from each other according to the one-way ANOVA with Tukey's multiple comparison test $(\mathrm{p} \leq$ $0.01)$.

G. F1 Affects the Production of Exopolysaccharides but not of Rhamnolipids in PAO1
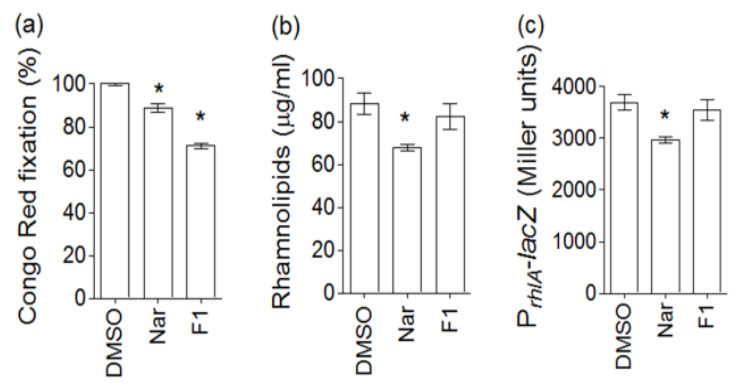

Fig. 10.Effect of F1 on exopolysaccharides and rhamnolipids production in PAO1 (a) Congo Red $(40 \mu \mathrm{g} / \mathrm{ml})$ exopolysaccharides binding assay in the presence of F1 $200 \mu \mathrm{g} / \mathrm{ml}$, naringenin (Nar 4 $\mathrm{mM}$ ) or DMSO $1 \%$ after $24 \mathrm{~h}$ of incubation. Congo red was quantified in the supernatants by absorbance measurements at $\mathrm{A}_{490}$ and expressed in \% of control conditions (DMSO). (b) Quantification of rhamnolipids production in the presence of F1 $200 \mu \mathrm{g} / \mathrm{ml}$, Nar $4 \mathrm{mM}$ or DMSO $1 \%$ after $24 \mathrm{~h}$ of incubation. Rhamnolipids production was measured using methylene-blue-based method and expressed in $\mu \mathrm{g} / \mathrm{ml}$ (see Material and Methods for details). (c) Effect of F1 on rhlAgene expression following $18 \mathrm{~h}$ of incubation. Gene expression was measured as the $\beta$-galactosidase activity of the lac $Z$ gene fusions and expressed in Miller units. All experiments were performed in triplicate with three independent assays. Error bars represent the standard error of the mean and the asterisks indicate samples that are significantly different from control condition (Student's t test, $\mathrm{p} \leq 0.01$ ).

As shown in Fig. 10(a), the polysaccharides production, estimated through the Congo red binding test, was reduced by $31.0 \pm 1.2 \%$ in the presence of $\mathrm{F} 1$, compared to control conditions. By contrast, the production of rhamnolipids was not significantly affected (Fig. 10b). In accordance, the rhlA gene expression encoding 3-(3hydroxyalkanoyloxy)alkanoic acids (the precursor of rhamnolipids) [24] is not affected by F1 (Fig. 10c).

\section{DISCUSSION AND CONCLUSION}

The present study evidences that the D. trichocarpa bark (DTB) apolar extract presents an unattractive bactericidal activity but an effective anti-virulence activity implicating the QS systems and biofilm formation (Fig. 1, S1). This presumably supports the healing properties of DTB in Malagasy traditional practices [6]. Following the chromatographic fractionation of the extract, the first eluted fraction F1 has been shown to inhibit the formation of PAO1 biofilm (Fig. 2), disrupt one-day old preformed biofilm structure (Fig. 8) and increase the susceptibility of biofilm-encapsulated bacteria to antibiotic treatment (Fig. 9). Interestingly, fluorescence microscopy revealed that PAO1 fails to form a compact micro-colonies network (Fig. 5) and bacterial motility analysis evidenced a defect in flagellum-dependent motilities (swimming and swarming) but not twitching motility (Fig. 7), a flagellumindependent motility-type [25]. This suggests that F1 may affect the early stage of biofilm formation, presumably through a direct or an indirect effect on the flagellum formation and/or function in PAO1. Indeed, studies support that flagellum is important for biofilm formation in PAO1 as a non-motile strain (carrying a mutation in flgK - hook-filament junctional protein) fails to swim and to attach onto PVC surfaces [22, 26]; the authors concluded to a role of PAO1 flagella in cell-to-surface interactions in the initial stages of biofilm formation. Besides, PAO1 flagellum components, such as the flagellar cap protein FliD and flagellinFliC, are important for adhesion since $\Delta$ fliCand $\Delta$ fliDmutants do not bind biotic surface such as human airway mucins [27]. Thus, the functional characterization of PAO1 flagellum may be a credible starting point to elucidate the inhibition of 
biofilm formation induced by $\mathrm{F} 1$ and therefore deserves further exploration. Curiously, this biofilm inhibition process occurred in PAO1 as long as $\mathrm{F} 1$ is provided in the growth medium but seems to be somewhat reversible when F1 is eliminated (Fig. 6), suggesting a nonpermanent modification in the presumed target pathway. The partial recovery of biofilm structure might be explained by a residual presence of $\mathrm{F} 1$ components after the washing steps, which should be confirmed.

The loss of the typical architecture of the preformed biofilm (Fig. 8) and the consequently increased susceptibility of bacteria to antibiotic treatment (Fig. 9) are probably connected with the decreased exopolysaccharides production (Fig. 10); these major components of the biofilm matrix are known to be crucial for bacterial adhesion, structuration as well as the post-attachment maintenance of biofilms [16, 28, 29]. Besides, exopolysaccharides (particularly Pel and Psl polysaccharides) are important for the protection of biofilm-encapsulated bacteria against antimicrobial compounds; indeed Billings et al. [30] have shown that P. aeruginosaPsl mutants $(\mathrm{PAO} 1 \Delta \mathrm{ps} \mathrm{AB})$ are three-fold more sensitive to antibiotic treatment than the wild type. Thus, the quantitative reduction of exopolysaccharides induced by F1 certainly explains, at least in part, the effectiveness of the antibiotic levofloxacin-F1 combined treatment (Fig. 8). However, qualitative alteration should be also addressed and further experiments are required to shed light on the F1 targets with regard to exopolysaccharides matrix.

Several natural products have been reported to impact biofilm formation [31]. For instance, and similarly to F1, an apolar (toluene) ginger extract does not exert anti-QS activity but inhibits the production of exopolysaccharides in P. aeruginosa PA14. However, in contrary to F1, this ginger extract increases flagellum-dependent cell motility, suggesting a different target pathway [32]. Finally, F1 is a crude fraction containing multiple compounds that could present several targets with different scores of affinity and/or present more than one inhibition process. Thus, the elucidation of the molecule(s) responsible for antibiofilm activity and the assessment of its (their) impact on different mechanisms regulating biofilm formation in $\mathrm{P}$. aeruginosa should allow us better understanding of the complex processes induced by F1. Experiments are now in progress in order to isolate and identify the active principle(s) to better characterize the potential target(s) responsible for the observed biofilm phenotypes.

\section{ACKNOWLEDGEMENTS}

Labtani Quentin is a PhDstudent of the FRIA (Fonds pour la formation à la Recherche dans l'Industrie et dans l'Agriculture, Belgium). This research was supported by the project PIC-Madagascar 2009 of the ARES-CCD (Académie de Recherche et d'Enseignement SupérieurCommission Coopération au Développement, Belgium) and by David and Alice Van Buurenfoundation, Université Libre de Bruxelles. We would like to thank Professor Junichi Kato, Hiroshima University (Department of Molecular Biotechnology), Japan, for kindly providing plasmids $\mathrm{p} \beta 01$, $\mathrm{p} \beta 02$; Professor Helmut Görisch, Technische Universität Berlin (Fachgebiet Technische Biochemie, InstitutfürBiotechnologie), Germany, for providing plasmid pTB4124; and Professor David Perez Morga (Centre for Microscopy and Molecular Imaging and Institut de Biologie et de MédecineMoléculaire, UniversitéLibre de Bruxelles), Belgium, for providing access to the Leica DM IRE2 inverted fluorescence microscope.

\section{REFERENCES}

[1] B. Mahesh, and S. Satish, "Antimicrobial activity of some important medicinal plant against plant and human pathogens," World Journal of Agricultural Sciences, vol.4, no. 5, pp. 839-843, 2008.

[2] A. Upadhyay, I. Upadhyaya, A. Kollanoor-Johny, and K. Venkitanarayanan, "Combating Pathogenic Microorganisms Using Plant-Derived Antimicrobials: A Minireview of the Mechanistic Basis," BioMed Research International,2014, vol. 18, 2014

[3] H.-J. Wu, A.H.J. Wang, and M.P. Jennings, "Discovery of virulence factors of pathogenic bacteria," Current Opinion in Chemical Biology, vol.12, pp. 93-101, 2008.

[4] K. Ivanova, M.M. Fernandes, and M.M. Tzanov, "Current advances on bacterial pathogenesis inhibition and treatment strategies," Microbial pathogens and strategies for combating them: science, technology and education, vol.1, pp. 322-336, 2013.

[5] D. J. Du Puy, J. N. Labat, R. Rabevohitra, J.-F. Villiers, J. Bosser, and J. Moat, "The Leguminosae of Madagascar," Royal Botanic Gardens, Kew, Richmond, United Kingdom, 2002.

[6] R.H.M.J. Lemmens, Dalbergiatrichocarpa Baker. [Internet] Fiche de Protabase. D. Louppe, A.A. Oteng-Amoako, M. Brink, (Editeurs). PROTA (Plant Resources of Tropical Africa/Ressourcesvégétales de l'Afriquetropicale), Wageningen, The Netherlands, 2008.

[7] T. Rasamiravaka, L. Pottier, J. Huet, et al, "Pseudomonas aeruginosa biofilm formation and persistence, along with the production of quorum sensing-dependent virulence factors, are disrupted by a triterpenoidcoumarate ester isolated from Dalbergiatrichocarpa, a tropical legume," PLoS ONE vol. 10, no. 7, e0132791, 2015.

[8] O.M. Vandeputte, M. Kiendrebeogo, S. Rajaonson, et al., "Identification of catechin as one of the flavonoids from Combretum albiflorum bark extract that reduces the production of quorum-sensing controlled virulence factors in Pseudomonas aeruginosa PAO1," Applied Environment Microbiology, vol.76, no. 1, pp. 243-253, 2010.

[9] T.Rasamiravaka, A. Jedrzejowski, M. Kiendrebeogo, et al., "Endemic Malagasy Dalbergia species inhibit quorum sensing in Pseudomonas aeruginosa PAO1," Microbiology, vol. 159, Pt. 5, pp. 924-938, 2013.

[10] L. Chérigo, R. Pereda-Miranda, and S. Gibbons, "Bacterial resistance modifying tetrasaccharide agents from Ipomoea murucoides," Phytochemistry,vol.70, no. 2, pp. 222-227, 2009.

[11] P.N. Okusa, O. Penge, M. Devleeschouwer, and P. Duez, "Direct and indirect antimicrobial effects and antioxidant activity of Cordiagilletii De Wild (Boraginaceae)," Journal of Ethnopharmacology, vol.112, no. 3, pp. 476-481, 2007.

[12] J.J., Kiplimo, N.A. Koorbanally, and H. Chenia, "Triterpenoids from VernoniaauriculiferaHiern exhibit antimicrobial activity," African Journal of Pharmacy and Pharmacology, vol.5, pp. 11501156, 2011.

[13] A.M. Tennenberg, B. Neelam, W. Shu-Chen, and J. Kahn, "Pneumonia due to Pseudomonas aeruginosa: the levofloxacin clinical trials experience," Current Medical Research and Opinion, vol. 22, no. 5, pp. 843-850, 2006.

[14] T. Rasamiravaka, O.M. Vandeputte, C. Stévigny, P. Duez, and M. El Jaziri, "Pseudomonas aeruginosa biofilm formation and persistence, along with the production of quorum sensingdependent virulence factors, are disrupted by a triterpenoidcoumarate ester isolated from Dalbergiatrichocarpa, a tropical legume," PloS One, vol. 10, no. 7, e0132791, 2015.

[15] N.M. Pinzon, and L.K. Ju, "Analysis of rhamnolipid biosurfactants by methylene blue complexation," Applied Microbiology and Biotechnology, vol. 82, no. 5, pp. 975-981, 2009.

[16] L. Ma, K.D. Jackson, R.M. Landry, M.R. Parsek, and D.J. Wozniak, « Analysis of Pseudomonas aeruginosa conditional Psl variants 
reveals roles for the Psl polysaccharide in adhesion and maintaining biofilm structure postattachment," Journal of Bacteriology, vol.188, pp. 8213-8221, 2006.

[17] D.G. Ha, S.L. Kuchma, and G.A. O'Toole, "Plate-based assay for swimming motility in Pseudomonas aeruginosa," Pseudomonas Methods and Protocols, pp. 59-65, Edited by Springer New York, 2014.

[18] A. Bala, R. Kumar, and K. Harjai, "Inhibition of quorum sensing in Pseudomonas aeruginosa by azithromycin and its effectiveness in urinary tract infections," Journal of Medical Microbiology, vol.60, no. 3 , pp. $300-306,2011$

[19] O.M. Vandeputte., M. Kiendrebeogo, T. Rasamiravaka, et al., "The flavanonenaringenin reduces the production of quorum sensingcontrolled virulence factors in Pseudomonas aeruginosa PAO1," Microbiology, vol. 157, Pt. 7, pp. 2120-2132, 2011.

[20] X. Zhang, and H. Bremer, "Control of the Escherichia coli rrnB P1 promoter strength by ppGpp," The Journal of Biological Chemistry, vol.270, pp. 11181-11189, 1995

21] F. Varaigne, and D. Hubert, "Cystic fibrosis. Evidence based respiratory medicine: 2nd update workshop of the SPLF," Revue des Maladies Respiratoires, vol. 21, pp. 849-852, 2004

[22] K.B. Barken, S.J. Pamp, L. Yang, et al., "Roles of type IV pili, flagellum-mediated motility and extracellular DNA in the formation of mature multicellular structures in Pseudomonas aeruginosabiofilms," Environmental Microbiology, vol.10, pp. 2331-2343, 2008.

[23] J.D. Shrout, D.L. Chopp, C.L. Just, M. Hentzer, M. Givskov, and M.R. Parsek, "The impact of quorum sensing and swarming motility on Pseudomonas aeruginosa biofilm formation is nutritionally conditional," Molecular Microbiology, vol.62, pp. 1264-1277, 2006

[24] E. Déziel, F. Lépine, S. Milot, and R. Villemur, "rhlA is required for the production of a novel biosurfactant promoting swarming motility in Pseudomonas aeruginosa: 3-(3hydroxyalkanoyloxy)alkanoic acids (HAAs), the precursors of rhamnolipids," Microbiology, vol. 149, Pt. 8, pp. 2005-2013, 2003.

[25] L.L. Burrows, "Pseudomonas aeruginosa twitching motility: type IV pili in action," Annual Review of Microbiology, vol.66, pp. 493$520,2012$.

[26] G.A. O'Toole, and R. Kolter, "Flagellar and twitching motility are necessary for Pseudomonas aeruginosa biofilm development," Molecular Microbiology, vol.30, pp. 295-304, 1998.

[27] J. Haiko, and B. Westerlund-Wikström, "The Role of the Bacterial Flagellum in Adhesion and Virulence," Biology, vol. 2, 1242, 2013.

[28] A. Ghafoor, I.D. Hay, and B.H.A. Rehm, "Role of exopolysaccharides in Pseudomonas aeruginosa biofilm formation and architecture. Applied and Environmental Microbiology, vol. 77, no. 15 , pp. 5238-5246, 2011.

[29] K. Jonas, Ö. Melefors, and U. Römling, "Regulation of c-di-GMP metabolism in biofilms," Future Microbiology, vol.4, no. 3, pp. 341-358, 2009.

[30] N. Billings, M.R. Millan, M. Caldara, R. Rusconi, Y. Tarasova, R.Stocker, and K. Ribbeck, "The extracellular matrix component Psl provides fast-acting antibiotic defense in Pseudomonas aeruginosa biofilms," PLoS pathogens, vol. 9, no. 8, e1003526, 2013.

[31] T. Rasamiravaka, Q. Labtani, P. Duez, and M. El Jaziri, "The formation of biofilms by Pseudomonas aeruginosa: a review of the natural and synthetic compounds interfering with control mechanisms," BioMed Research International, Article ID 759348, 2015 .

[32] H-S. Kim and H-D.Park, "Ginger Extract Inhibits Biofilm Formation by Pseudomonas aeruginosa PA14," PLoS One, vol. 8, no. 9, Article ID e76106, 2013.

\section{BIOGRAPHY}

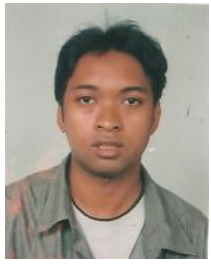

Tsiry Rasamiravaka $\mathrm{MD}, \quad \mathrm{PhD}$ Physician and microbiologist at University of Antananarivo (Madagascar), responsible of research at the Laboratory of Research and Training in Medical Biology (University of Antananarivo) and scientist collaborator at the Laboratoire de BiotechnologieVégétale (UniversitéLibre de Bruxelles, Belgium). Fields of interest: Plants-Bacteria interaction with particular emphasis on the modulation of bacterial virulence factors expression through cell-to-cell communication and the exploration of medicinal and/or endemic plants as source of unrevealed anti-virulence compounds.

\section{SUPPLEMENTARY DATA}

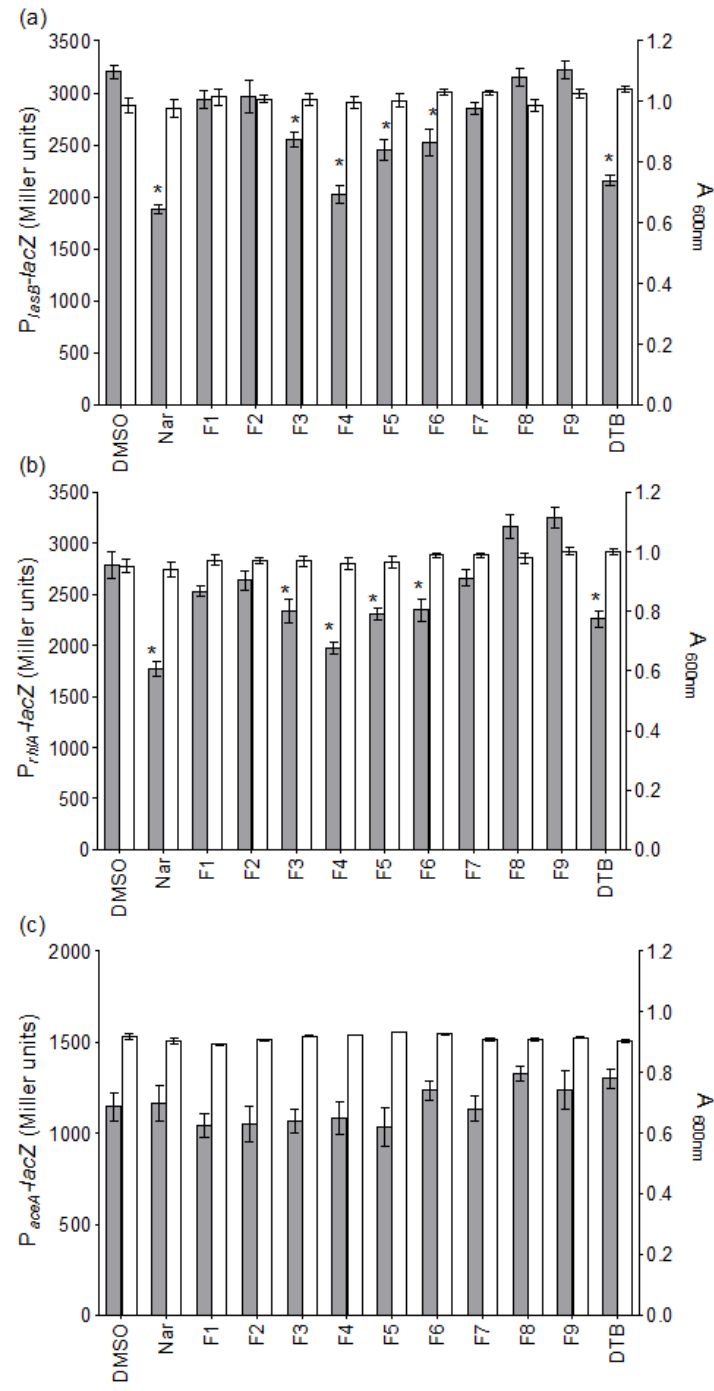

Fig. S1. Effect of DTB extract and fractions F1-F9 on QSdependent (lasBand rhlA) genes expression in $\mathrm{P}$. aeruginosaPAO1.

Effect of DTB extract and fraction F1-F9 at $200 \mu \mathrm{g} / \mathrm{ml}$ on (a) lasB, (b) rhlA and (c) aceAexpression (grey bar) and growth turbidity (clear bar) following $18 \mathrm{~h}$ of growth. Naringenin (Nar 4mM) was used as positive control. Gene expression was measured as the $\beta$-galactosidase activity of the lacZ gene fusions and expressed in Miller units. All experiments were performed in triplicate with three independent assays. Error bars represent the standard errors of the means and asterisks indicate samples that are significantly different from control condition (DMSO) (Student's t tests; $\mathrm{p} \leq 0.01$ ). 


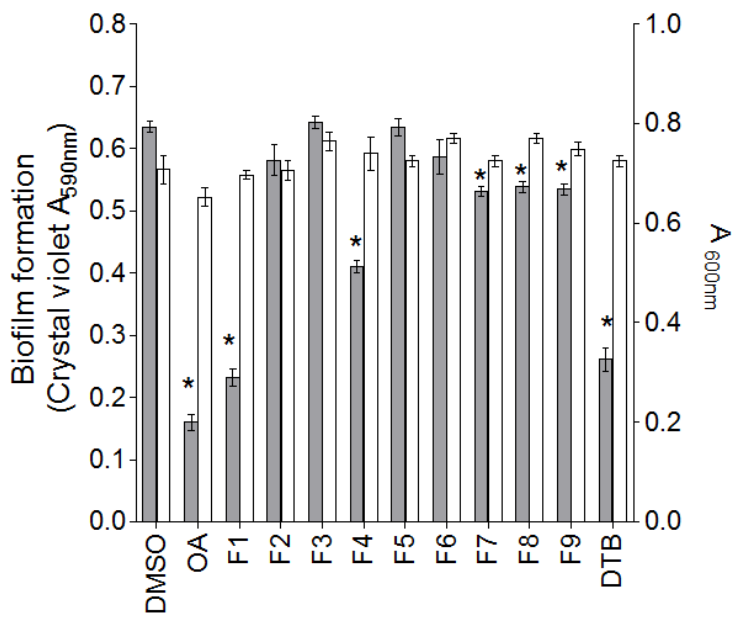

Fig. S2. Effect of DTB extract and fractions F1-F9 on biofilm formation in $\mathrm{P}$. aeruginosaPAO1.

Biofilm formation (grey bar) and growth turbidity (clear bar) of $\mathrm{P}$. aeruginosa PAO1 grown in minimal medium supplemented with DMSO $1 \%$ or oleanolic acid $800 \mu \mathrm{M}$ (OA), DTB extract or fractions F1-F9 at $200 \mu \mathrm{g} / \mathrm{ml}$ after incubation without agitation at $37^{\circ} \mathrm{C}$ for $24 \mathrm{~h}$. Biofilm formation was quantified by crystal violet staining and measured at $\mathrm{A}_{590 \mathrm{~nm}}$. The cell density of the bacteria was assessed $\mathrm{A}_{600 \mathrm{~nm}}$. All experiments were performed in triplicate with three independent assays. Error bars represent the standard error of the mean and the asterisks indicate samples that are significantly different from DMSO control (Student's t test, $\mathrm{p} \leq 0.01$ ). 